\title{
FEMINISMO ESTATAL SOB A PRESIDÊNCIA LULA: O CASO DA SECRETARIA DE POLÍTICAS PARA AS MULHERES ${ }^{1}$
}

\author{
Simone R. Bohn
}

\begin{abstract}
Resumo
O feminismo estatal prosperou sob a Presidência Lula? Este artigo analisa dois aspectos relativos à Secretaria de Políticas Públicas para Mulheres (SPM). Primeiro, o grau de comprometimento federal com essa agência. Segundo, o relacionamento da SPM com o movimento de mulheres. Utilizando-se de dados quantitativos longitudinais e de entrevistas em profundidade com femocratas e ativistas, este artigo indica que as Presidências Lula contribuíram para o fortalecimento institucional da SPM, dada a localização desta no aparelho de estado, seu status, e sua dotação orçamentária. Além disso, a composição interna da SPM, seus mecanismos de consulta e seu padrão de financiamento de projetos criaram uma dinâmica de cooperação (e não de cooptação ou captura) com o movimento de mulheres-algo visto como crucial ao êxito do feminismo de estado.
\end{abstract}

Palavras-chave: Mulher; Feminismo; Estado; Políticas Públicas; Femocrata.

\begin{abstract}
Did the state feminism prosper under Lula's presidency? This article analyzes two elements pertaining to the Secretariat of Public Policies for Women (SPM). First, the degree of commitment of the federal government with this agency. Second, the relationship between SPM and organized women. Using longitudinal data and in-depth interviews with femocrats and activists, this article shows that Lula's presidencies enhanced SPM's institutional strength, given its place within the state apparatus, its status and its budget. Furthermore, it also shows that SPM's internal composition, its consultation process and its funding program have created a dynamic of cooperation (and not of cooptation or capture) with the women's movement, which is deemed essential to state feminism's success.
\end{abstract}

Keywords: Women; Feminism; State; Public Policies; Femocrat.

\section{Introdução}

A mobilização do estado com o objetivo de implementar políticas com um componente de gênero é uma estratégia importante para a diminuição da desigualdade entre homens e mulheres em uma sociedade. As agências estatais de políticas públicas para as mulheres (APM) - embora não sejam o único mecanismo para tal - desempenham

\footnotetext{
1 Este trabalho foi realizado com o auxílio de um financiamento da International Development Research Centre (IDRC), Ottawa, Canadá. Texto inicialmente apresentado na conferência da American Political Science Association em 2009. Sou grata aos comentários de Karen Beckwith.
} 
um papel fundamental nesse processo e correspondem a uma importante reivindicação do movimento de mulheres em diversos países - além do Brasil - desde pelo menos a Quarta Conferência Internacional de Mulheres em Beijing em 1995. Como seu próprio nome sugere, essas agências são entidades integrantes da burocracia estatal, lideradas pelas chamadas femocratas e que buscam a aprovação e implementação de políticas públicas que melhorem o status desigual das mulheres nos mais diversos campos de interação social.

Este artigo analisa o feminismo estatal sob a Presidência Lula, isto é, o processo de criação e o padrão de funcionamento da Secretaria de Políticas Públicas para Mulheres (SPM). O objetivo primordial é verificar quão exitosa tem sido essa APM desde sua criação em 2003. Sucesso aqui é concebido em pelo menos duas dimensões. Em primeiro lugar, as agências de políticas públicas para a mulher consideradas exitosas são aquelas que têm força institucional suficiente para abrir espaço para as demandas do movimento de mulheres no interior das arenas decisórias estatais; ou seja, são capazes de introduzir um componente de gênero nas discussões sobre políticas públicas. Em segundo lugar, as APMs cumprem seu objetivo quando as políticas implementadas pelo estado correspondem em grande parte às demandas dos movimentos de mulheres. Portanto, a força institucional da APM é essencial; mais importante ainda, no entanto, é um trabalho de cooperação entre a APM e os movimentos de mulheres, que resulte no efetivo enfrentamento de problemas concretos que afetam as mulheres em geral.

Tendo em vista essa complexa noção de sucesso, este artigo busca analisar dois elementos relativos à SPM. Primeiro, o tratamento dado a essa Secretaria pelo governo Lula. A meta é verificar a importância atribuída à SPM pela administração federal do Partido dos Trabalhadores (PT). A SPM é somente um gesto simbólico do PT ao movimento de mulheres ou possui efetivo poder institucional? E se sim, como este último se manifesta? Em segundo lugar, qual tem sido a relação entre a SPM e o movimento de mulheres? Trata-se de uma dinâmica de cooperação? Ou de uma situação de cooptação do 
movimento de mulheres pela APM? Ou ainda, de uma interrelação na qual o movimento de mulheres captura e coloniza essa arena do aparelho de estado?

A fim de responder essas questões, este texto se divide em quatro partes. A primeira parte resume a literatura sobre feminismo estatal e extrai hipóteses para a análise do caso brasileiro. A segunda seção se centra no processo de criação da Secretaria de Políticas Públicas para as Mulheres na administração Lula e, especialmente, na descrição das diferenças entre essa APM e suas antecessoras que existiram sob outros governos. A terceira parte examina a atuação da SPM e seu padrão de relação com o movimento de mulheres no Brasil.

A seção final indica que, em termos institucionais, apesar de a SPM sob a Presidência Lula representar um importante avanço em comparação com as APMs que as antecederam, sua institucionalização no interior do aparelho de estado - e, portanto, sua continuidade nos termos atuais - não pode ser tomada como um fato consumado. Similarmente, mudanças na liderança da SPM podem alterar, de maneira significativa, sua dinâmica atual de cooperação com o movimento de mulheres.

\section{Feminismo Estatal: Criação e Atuação das APMs}

A institucionalização da presença feminina no aparelho de estado possui um efeito catalítico para o avanço da causa das mulheres no mundo democrático. Essa é a principal conclusão de um importante segmento da literatura sobre mulher e política que floresceu nos últimos quinze anos (LOVENDUSKI, 2005a; MAZUR, 2001; MCBRIDE STETSON e MAZUR, 1995; OUTSHOORN, 2004; SAWER, 1990; STETSON, 2001). Uma ativa agência estatal de políticas para mulheres, capaz de criar redes extensas no interior da burocracia pública, de introduzir uma perspectiva de gênero às arenas decisórias estatais e cujo plano de ação incorpora demandas do movimento de mulheres é essencial à formulação, adoção e implementação de políticas públicas que efetivamente atenuem ou eliminem desigualdades de gênero. 
Diversos fatores impactam o grau de sucesso dessas agências de políticas para a mulher, ou seja, sua capacidade de introduzir um olhar de gênero em instâncias decisórias da burocracia estatal e de viabilizar a implementação de políticas públicas que contemplem as demandas das mulheres em geral. Esses fatores incluem as qualidades de liderança das femocratas, o grau de profissionalismo das APMs, a relação destas últimas com o movimento de mulheres, e o grau de abertura do sistema político em termos do acesso de atores da sociedade civil às arenas decisórias estatais (LOVENDUSKI, 2005a; MAZUR, 2001; MCBRIDE STETSON E MAZUR, 1995; OUTSHOORN, 2004; MCBRIDE STETSON, 2001). Este artigo se focará em dois outros fatores. O primeiro diz respeito ao perfil ideológico do governo sob o qual a APM desenvolve suas atividades. Governos de partidos políticos ou coalizões progressistas são considerados mais conducentes tanto à implantação de uma APM (caso uma inexista), quanto ao incremento de sua força institucional no interior da burocracia estatal (MCBRIDE STETSON e MAZUR, 1995). Isso porque partidos progressistas usualmente incorporam em sua plataforma programática questões de eqüidade de gênero, o que os aproxima dos objetivos do movimento de mulheres e facilita o processo de legitimação de uma agência de políticas públicas para a mulher. No caso brasileiro, portanto, a expectativa é de que, sob a presidência de um partido político caracteristicamente progressista como o Partido dos Trabalhadores (PT), a SPM tenha adquirido força institucional no interior do aparelho de estado; isto é, seja dotada de pessoal, capacidade técnica, autonomia decisória para assuntos internos e recursos financeiros que the permitam exercer suas atividades de maneira efetiva.

Esse primeiro elemento se refere à relação entre o governo (usualmente o governo central) e as APMs. Um segundo fator que será examinado pauta a relação entre essas entidades e a sociedade civil organizada, particularmente o movimento de mulheres. De acordo com Mazur e McBride Stetson (2007), a mera existência de uma agência de políticas públicas para mulheres é insuficiente. Em primeiro lugar, porque pode gerar o que essas autoras chamam de casos de não 
resposta: ou seja, situações nas quais a despeito da presença de uma APM no interior do aparelho de estado, uma perspectiva de gênero não é adotada pelas principais arenas decisórias públicas e também não há ganhos significativos para as mulheres em termos de políticas públicas. Segundo, porque pode resultar na cooptação do movimento de mulheres pela APM ou, alternativamente, na captura da APM pelas organizações de mulheres. Os casos mais exitosos de feminismo estatal - ainda de acordo com Mazur e McBride Stetson (2007) - são aqueles nos quais há uma dinâmica de cooperação entre a APM e as organizações de mulheres, na qual a segunda informa a primeira a respeito dos principais objetivos gerais a serem alcançados. No entanto, nem a APM perde sua autonomia decisória nem o movimento de mulheres passa a se confundir com o estado. Pelo contrário, por um lado, a APM continuamente busca criar redes no interior do estado que levem à adoção de uma perspectiva de gênero no processo decisório (SAWER, 1995) e, por outro, o movimento de mulheres continuamente exerce pressão sobre o estado para a implementação de políticas públicas que revertam o status desigual das mulheres (BYSTYDZIENSKI, 1995).

Portanto, no caso da relação entre a APM e a sociedade civil organizada, o objetivo deste artigo é analisar em que medida a SPM mantém uma dinâmica de cooperação - ou não - com o movimento de mulheres. Esse é o objeto da terceira seção deste artigo. Entretanto, antes de discutir a relação entre a APM brasileira e as organizações de mulheres, o texto descreverá primeiro, na próxima seção, o processo de criação da SPM e o tratamento concedido a esta agência pela administração Lula.

\section{A Criação da SPM sob Lula}

A Secretaria de Políticas Públicas para Mulheres não é a primeira agência da burocracia federal dedicada à promoção da igualdade de gênero. Antes de sua criação em 2003, o Conselho Nacional de Defesa dos Direitos da Mulher (CNDM) era a agência governamental dedicada às questões dos direitos das mulheres. 
As circunstâncias de criação do CNDM diferem bastante do processo de formação da SPM. Em 1984, no decorrer da transição para a democracia, o movimento de mulheres (ALVAREZ, 1990) propôs a Tancredo de Almeida Neves a criação de uma agência governamental especialmente dedicada aos assuntos das mulheres. Em Agosto de 1985, a Lei n. 7.353 criou o Conselho - o CNDM (BRASIL, 1985).

O CNDM exerceu suas atividades no interior do Ministério da Justiça e foi exitoso no avanço de diversas leis referentes a uma variedade de tópicos, como a saúde da mulher, regulação de profissionais urbanas e rurais em que mulheres são a maioria, violência contra a mulher, medidas contra o racismo e o estabelecimento de centros infantis (ou creches). As maiores conquistas do Conselho ocorreram durante o processo de elaboração do texto constitucional de 1988. O chamado lobby do batom conseguiu aprovar $80 \%$ de sua plataforma de ação (AGÊNCIA BRASIL, 2008; Entrevista com Márcia Leporace em Brasília, 5 de dezembro de 2007). De acordo com os participantes do lobby do batom apoiado pelo CNDM e dos autores da chamada Carta das Mulheres Brasileiras ao Congresso (CNDM, 1986), suas maiores conquistas foram o reconhecimento da parte do estado de que o acesso ao planejamento familiar é um direito da mulher e que são responsabilidade do estado reduzir desigualdades de gênero no mercado de trabalho e criminalizar a violência contra a mulher no âmbito doméstico (AGÊNCIA BRASIL, 2008).

Como reação às suas importantes conquistas, a força institucional do CNDM foi reduzida em 1989 pelo então Ministro da Justiça, quando este nomeou à Executiva do Conselho membros sem quaisquer vínculos com o movimento de mulheres e reduziu a agência a um órgão meramente consultivo. Em 1990, sob a Presidência Collor (1989-1991), o Conselho sofreu perdas ainda maiores: perdeu sua autonomia administrativa e financeira. Esses eventos confirmam duas tendências observadas em outros casos nacionais. Primeiro, agências de políticas públicas para a mulher que são precariamente institucionalizadas tendem a depender da existência de um chefe de governo bem-intencionado e com simpatia pela causa das mulheres. 
Segundo, partidos políticos ou lideranças sem vinculação com causas sociais progressistas, como o caso da administração Collor, tendem a não apoiar o processo de institucionalização das máquinas estatais de mulheres (LOVENDUSKI, 2005b).

As duas presidências social-democratas de Fernando Henrique Cardoso (1995 - 1998 e 1999 - 2002) não reverteram de maneira significativa o status depreciado do Conselho. Entretanto, a segunda administração Cardoso inovou ao criar a Secretaria dos Direitos das Mulheres (SEDIM) em 2002, em resposta às pressões de organizações de mulheres. A criação da SEDIM foi recebida por representantes do movimento de mulheres como uma importante vitória ${ }^{2}$, uma vez que esta agência teria a habilidade de criar redes com outros ministérios no que se refere ao desenho de políticas públicas e seria dotada de poder para implementar medidas concretas. Não obstante, a SEDIM, na prática, desapontou a expectativa inicial. Esta agência permaneceu localizada no interior do Ministério da Justiça, o que limitou significativamente sua esfera de ação (ARTICULANDO, 2002b). Além disso, a legislação que a criou não continha uma definição clara de suas atribuições e de sua estrutura administrativa (SPM, 2008b).

O desenho institucional da APM e sua localização no interior do aparelho de estado foram questões bastante debatidas pelas organizações de mulheres no Brasil (JUREMA, 2001). Em sintonia com as discussões da Quarta Conferência Mundial das Mulheres em Beijing em 1995, o movimento de mulheres no Brasil claramente entendeu a necessidade de localizar a APM no interior do gabinete da Presidência da República e explicitamente passou a advogar por esta causa (ARTICULANDO, 2002b; AMB, 2000).

Essas propostas para o fortalecimento de uma APM se tornaram parte das promessas de campanhas de um dos candidatos presidenciais em 2002, Luiz Inácio Lula da Silva, do Partido dos Trabalhadores. Uma vez eleito, Presidente Lula (2003 - 2006 e desde 2006) cumpriu suas

\footnotetext{
${ }^{2}$ A advogada Solange Bentes Jurema, ex-presidente do CNDM e da SEDIM, caracterizou a última como "uma vitória para as mulheres, e a tendência agora [em 2002] é elas avançarem mais" na conquista de espaços de poder no interior do estado (Articulando, 2002a, p. 1).
} 
promessas de campanha e criou a Secretaria Especial de Políticas Públicas para Mulheres (SPM) por meio da Medida Provisória n. 103, de 2003 (BRASIL, 2003a) - mais tarde convertida na Lei n. 10.683 (BRASIL, 2003b). A medida foi propagandizada pela nova Presidência como a realização do "compromisso do governo federal com as mulheres do país" (SPM, 2009, p. 1).

No que tange às suas atribuições, de acordo com a descrição da SPM de suas próprias atividades, esta agência busca advogar pelas mulheres brasileiras a partir do governo federal e desenvolver parceiras com as mais diversas entidades governamentais, com o intuito de adicionar um componente de gênero às políticas públicas, para que as mulheres brasileiras possam obter cidadania plena (SPM, 2009). Interessantemente, o CNDM não foi extinto. Pelo contrário, é parte ativa da SPM, o que significa que toda a experiência acumulada por essa entidade foi incorporada pela nova agência de políticas públicas para mulheres.

Além dessa presença do CNDM, há pelo menos duas outras diferenças entre a SPM e suas predecessoras. Em primeiro lugar, a SPM está localizada no epicentro do poder num regime presidencial - o gabinete presidencial. Conforme mencionado anteriormente, esta localização torna menos difícil a elaboração de uma auditoria de gênero das políticas públicas federais. Em segundo, a chefe da SPM tem status oficial de ministro de estado, o que se traduz não só em acesso próximo ao Presidente da República, como também em uma melhor estrutura administrativa e a capacidade de formular e implementar políticas públicas (BRASIL, 1999, art. 87). Desde sua criação, a SPM foi comandada por Emília Fernandes (por aproximadamente um ano) e por Nilcéia Freire (desde 2004).

O fato de o comando da SPM ter status de ministro tem outras implicações. Legalmente, significa que a chefia da SPM é uma posição comissionada, ou seja, é ocupada por alguém do círculo de confiança do presidente, que pode ser nomeado e demitido sem consulta a outros atores. Além disso, também implica que, em última instância, a SPM responde ao presidente - e não a entidades da sociedade civil. Portanto, 
sob essa perspectiva, a SPM se assemelha a qualquer outra agência governamental e sua continuidade depende do governo de plantão.

Apesar dessa natureza do vínculo da SPM com a Presidência, a administração Lula tem provido a agência com uma contínua oferta de recursos financeiros no decorrer dos anos. O orçamento anual da SPM aumentou de R\$ 4 milhões em 2003 para R\$ 55 milhões em 2008. O montante inicialmente alocado à SPM em 2009 foi de R\$ 72 milhões antes de a crise econômica forçar o governo federal (de acordo com os assessores do Presidente Lula) a cortar a distribuição de recursos aos ministérios e secretarias. Como porcentagem do orçamento anual do Gabinete da Presidência da República, os recursos da SPM cresceram de 1.14\% em 2003 para 5.89 em 2009 (Tabela 1).

Tabela 1 - Orçamento das Secretarias como porcentagem do orçamento do Gabinete da Presidência*

\begin{tabular}{|c|c|c|c|c|c|c|c|}
\hline Anos & $\mathbf{2 0 0 3}$ & $\mathbf{2 0 0 4}$ & $\mathbf{2 0 0 5}$ & $\mathbf{2 0 0 6}$ & $\mathbf{2 0 0 7}$ & $\mathbf{2 0 0 8}$ & $\mathbf{2 0 0 9}$ \\
\hline $\begin{array}{c}\text { SPM - Secretaria de Políticas } \\
\text { Públicas para as Mulheres }\end{array}$ & 1.14 & 4.22 & 2.84 & 3.14 & 5.89 & 6.06 & 5.89 \\
\hline $\begin{array}{c}\text { SEDH - Secretaria Especial de } \\
\text { Direitos Humanos }\end{array}$ & 7.79 & 12.45 & 9.00 & 9.35 & 13.42 & 14.29 & 13.00 \\
\hline $\begin{array}{c}\text { SEPPIR - Secretaria Especial } \\
\text { de Políticas de Promoção da } \\
\text { Igualdade Racial }\end{array}$ & $£$ & 3.48 & 2.19 & 3.16 & 4.41 & 2.63 & 2.07 \\
\hline
\end{tabular}

* Porcentagem da despesa empenhada (não da dotação inicial).

£ A SEPPIR foi criada ao final do ano de 2003; portanto, seu orçamento para este ano não é comparável ao das demais secretarias.

Fonte: Ccálculo do autor; dados do Tesouro Nacional (2003, 2004, 2005, 2006, 2007, 2008, 2009).

Em comparação com a magnitude dos recursos que o governo federal alocou às demais secretarias que pertencem ao Gabinete da Presidência da República, o orçamento da SPM não é nem o maior nem o menor. Em cada ano da administração Lula (até 2009), os recursos recebidos pela Secretaria Especial de Direitos Humanos (SEDH) corresponderam a aproximadamente o triplo dos recursos recebidos pela SPM, o que pode estar relacionado ao escopo de ação da SEDH - esta agência é responsável pela política de reparação aos mortos e desaparecidos durante o regime militar, pelo programa de proteção a testemunhas e pela luta contra a homofobia, o abuso policial e o trabalho escravo (SEDH, 2009). Até 2007, o orçamento da SPM foi 


\section{DOSSIÊ OS ANOS LULA}

bastante similar ao da Secretaria Especial de Políticas de Promoção da Igualdade Racial. Nos últimos dois anos completos (2008 e 2009), o orçamento da SPM tem crescido mais em comparação com o da SEPPIR. Isso pode estar relacionado com o esforço do governo federal concedido ao programa de enfrentamento à violência contra as mulheres, que é uma atividade desenvolvida a partir da $\mathrm{SPM}^{3}$.

Até 2007 , os cortes orçamentários sofridos pelas secretarias foram bastante similares. A partir de 2008, os cortes aos recursos da SPM têm sido menores que o das demais secretarias que fazem parte do Gabinete da Presidência. O que revela um grau considerável de comprometimento da administração Lula com essa agência de políticas públicas para as mulheres.

Portanto, desde 2003, a Presidência Lula vem dando importantes sinais de que sua administração apóia a APM brasileira de diversas formas. Em primeiro lugar, localizou a SPM numa arena decisória chave em sistemas presidencialistas. Em segundo, dotou a chefia da SPM do status de ministro, o que representa um importante avanço em relação às APMs que a predecederam. Finalmente, essa administração tem não só mantido como aumentado o montante de recursos financeiros à disposição da SPM. Além disso, os cortes orçamentários iniciados pelo governo federal também afetaram outras agências - em alguns anos, muito mais que a SPM. Em suma, as ações da administração Lula para com a SPM corroboram a hipótese da literatura sobre feminismo estatal, segundo a qual governos de partidos progressistas tendem a ser conducentes ao avanço de APMs no interior do aparelho de estado.

\footnotetext{
${ }^{3}$ Sem entrevistas com o Gabinete da Presidência é impossível determinar se este é o fator crucial.
} 
Tabela 2 - Corte no orçamento das secretarias

\begin{tabular}{|c|c|c|c|c|c|c|c|}
\hline Cortes orçamentários* & $\mathbf{2 0 0 3}$ & $\mathbf{2 0 0 4}$ & $\mathbf{2 0 0 5}$ & $\mathbf{2 0 0 6}$ & $\mathbf{2 0 0 7}$ & $\mathbf{2 0 0 8}$ & $\mathbf{2 0 0 9}$ \\
\hline $\begin{array}{c}\text { SPM - Secretaria de Políticas } \\
\text { Públicas para as Mulheres }\end{array}$ & 81.30 & 34.70 & 21.70 & 30.40 & 31.50 & 9.10 & 4.20 \\
\hline $\begin{array}{c}\text { SEDH - Secretaria Especial de } \\
\text { Direitos Humanos }\end{array}$ & 73.70 & 24.70 & 26.10 & 22.70 & 22.80 & 20.90 & 14.80 \\
\hline $\begin{array}{c}\text { SEPPIR - Secretaria Especial } \\
\text { de Políticas de Promoção da } \\
\text { Igualdade Racial }\end{array}$ & $£$ & 23.40 & 26.70 & 42.80 & 27.30 & 34.90 & 36.70 \\
\hline
\end{tabular}

* Porcentagem de recursos originalmente alocada às secretarias que nunca foram transferidas pelo Gabinete da Presidência (diferença, em termos percentuais, entre despesas executadas + restos a pagar e dotação atualizada).

$£$ A SEPPIR foi criada ao final do ano de 2003; portanto, seu orçamento para este ano não é comparável ao das demais secretarias.

Fonte: Cálculo do autor; dados do Tesouro Nacional (2003, 2004, 2005, 2006, 2007, 2008, 2009).

Como tem sido a relação da SPM com o movimento de mulheres? Há uma dinâmica de cooperação? Ou trata-se de um caso de cooptação ou de captura do aparelho de estado por movimentos sociais? A próxima seção decentra em três aspectos relativos a essa relação entre estado e sociedade civil: seu processo de criação de uma agenda de prioridades; a presença do CNDM em seu interior; e seu padrão de financiamento de projetos.

\section{A SPM em Ação}

Em Janeiro de 2003, quando a agência foi criada, uma das questões fundamentais postas à SPM tratou-se da busca de uma definição clara de sua plataforma de ação. Quais são os interesses das mulheres brasileiras e como estes se traduzem - ou podem ser traduzidos - em propostas concretas de políticas públicas? Em seu esforço para criar um plano abrangente de ação, a SPM evitou assumir a postura de que os interesses das mulheres brasileiras são dados ou sabidos de antemão. Ao invés de se utilizar de idéias do senso comum sobre prioridades para políticas de gênero ou somente das opiniões de especialistas sobre o tema, a SPM criou um esquema elaborado de consulta juntos às mais diversas organizações da sociedade civil articuladas ao redor da defesa dos interesses das mulheres brasileiras. Em outras palavras, a SPM buscou incluir e ouvir como a interseccionalidade (CRENSHAW, 1991; WELDON, 2008) entre gênero, raça e religião em uma sociedade com uma estrutura de classes 
altamente fragmentada molda percepções e demandas concretas sobre políticas de eqüidade de gênero. A Ministra Freire explicitamente elaborou esse ponto, dizendo que "[é] necessário afirmar as diferenças a fim de promover a igualdade" (SPM, 2004a, p. 14). Conferências estaduais e municipais foram realizadas entre janeiro e maio de 2004.

De acordo com as cifras oficiais, aproximadamente 120 mil mulheres brasileiras participaram nessas conferências (SPM, 2004a). Um total de 1.787 delegados de cada um dos estados e do Distrito Federal se congregaram em Brasília em junho de 2004. Além do número considerável de participantes, é também importante mencionar a decisão deliberada da SPM de sobre-representar a sociedade civil. A SPM determinou que $60 \%$ dos participantes da conferência nacional adviriam de organizações da sociedade civil, $30 \%$ seriam representantes de governos municipais e $10 \%$ de governos estaduais. Portanto, não só a SPM elaborou um mecanismo amplo de consulta, como também tentou evitar que a contribuição de mulheres presentes na máquina do estado em diferentes níveis de governo (as femocratas municipais e estaduais) ofuscasse a colaboração das mulheres que se encontram fora do aparelho estatal. A SPM utilizou os anais da conferência para, no final de 2004, criar sua plataforma de ação: um plano trianual (2005-2007), denominado Plano Nacional de Políticas Públicas paras as Mulheres $\left(\right.$ PNPM I) ${ }^{4}$.

O primeiro Plano Nacional, PNPM I, definiu quatro áreas de ação estratégica, a serem implementadas prioritariamente em 2006 e 2007 (uma vez que o planejamento orçamentário para 2005 já estava concluído quando o PNPM I foi posto em ação). As áreas são a) autonomia, igualdade no mercado de trabalho e cidadania; b) educação inclusiva e não-sexista; c) saúde das mulheres, direitos sexuais e reprodutivos; e d) enfrentamento à violência contra as mulheres. Essas quatro áreas foram traduzidas em 199 pontos de ação concreta. Além de uma definição clara da plataforma de ação, o PNPM I também criou

\footnotetext{
${ }^{4}$ O plano em si foi escrito por um grupo inter-ministerial coordenado pela SPM e composto por sete ministérios, representantes da Secretaria Especial de Promoção da Igualdade Racial (SEPPIR), uma agência estadual e outra municipal de políticas públicas para mulheres (SPM, 2004a).
} 
mecanismos para monitorar o processo de implementação. Um Comitê de Articulação e Monitoramento foi criado para o estabelecimento de um conjunto de critérios uniformes para a avaliação do sucesso na implementação de cada um dos pontos de ação concreta. Uma outra importante demanda - manifesta durante a Conferência Nacional e incorporada no plano nacional - foi a necessidade de aumentar a capacitação do estado (state capacity), nos âmbitos municipal e estadual, de estabelecer "uma rede de ações e serviços" públicos (SPM, 2004a, p. 74), de modo a criar condições para a efetiva implementação dos pontos de ação concreta.

Em 2006, a SPM publicizou um relatório oficial com os resultados preliminares do processo de implementação do PNPM I. Além de detalhar o grau de efetivação de cada um dos 199 pontos de ação, a SPM enfatizou que seus principais êxitos foram também seus maiores desafios $^{5}$. Em primeiro lugar, a tarefa de desenvolver tentáculos nas arenas decisórias foi extremamente onerosa - tal como em outros contextos nacionais (SAWER, 1995) - e envolveu convencer os tomadores de decisão de outras partes do governo a respeito da legitimidade da presença de femocratas e da importância de incluir um componente de gênero em suas decisões ${ }^{6}$. Em segundo, também oneroso foi o trabalho de convencer as autoridades de estados e municípios a respeito da importância de uma APM nas suas localidades. $\mathrm{Na}$ metade do ano de 2006, quando o primeiro relatório oficial foi emitido, existiam 110 APMs nos governos subnacionais brasileiros - em 2004, apenas 13 APMs estavam em funcionamento. Terceiro, no relatório, a SPM, através do seu Comitê de Articulação e Monitoramento, também reconheceu dificuldades para quantificar o montante de recursos gastos na implementação de cada um dos pontos de ação,

5 De acordo com esse primeiro relatório oficial, em 2006 a SPM já tinha começado a implementar ou tinha implementado plenamente 134 dos 199 pontos de ação concreta. Entretanto, como algumas medidas são muito mais importantes que outras, seria temerário utilizar esses números para uma avaliação do desempenho da SPM. Não obstante, a esmagadora maioria das participantes dos movimentos de mulheres entrevistadas para este artigo considera o trabalho da SPM excelente.

${ }^{6}$ Entrevista com Maria Cláudia do Canto Cabral, do Ministério da Cultura, que trabalha em conjunto com a SPM no Comitê de Monitoramento do Plano (em Brasília, 3 de dezembro de 2009). 
dada a complexidade inerente às políticas públicas e ao fato de algumas medidas terem sido executadas por ministérios cujas contas não permitem avaliar o gasto por ação temática.

Em 2007, a sociedade civil foi mais uma vez chamada para criar uma nova plataforma de ação para a SPM. A segunda Conferência Nacional de Políticas Públicas para Mulheres teve lugar em Brasília em 2007. Cerca de 200 mil mulheres participaram nos encontros municipais e estaduais (SPM, 2008b). Como no encontro anterior, houve sobrerepresentação da sociedade civil entre as 2.306 delegadas que participaram da Conferência Nacional. O Segundo Plano Nacional de Políticas Públicas, PNPM II, elaborado a partir dos anais da conferência, adicionou seis novos eixos de ação aos quatro estabelecidos pelo PNPM I, possui 94 objetivos, 56 prioridades e 388 pontos de ação concreta e refere-se aos anos 2008, 2009 e 2010. A maior parte das suas atividades, portanto, ainda estão ocorrendo.

O que esse processo de criação de uma plataforma de ação revela sobre a relação entre a SPM e a sociedade civil organizada? Em primeiro lugar, revela que a SPM tem se esforçado muito para incorporar a diversidade de vozes femininas em suas políticas. Seus planos nacionais de ação contêm medidas relacionadas tanto às demandas genéricas do movimento de mulheres - que afetam as mulheres brasileiras em geral - quanto medidas que afetam segmentos específicos do contingente feminino da população brasileira (CRENSHAW, 1991; WELDON, 2006), como trabalhadoras rurais, mulheres do campo e de floresta, mulheres indígenas e negras, mulheres jovens, mulheres idosas, empregadas domésticas, mulheres pobres e diversas interseções entre esses grupos. Até mesmo os grupos pró-vida (contrários à legalização e/ou descriminalização do aborto) fizeram parte dos processos de consulta e tiveram a chance de serem ouvidos.

Em segundo lugar, o processo de formulação e implementação de políticas públicas tem um grau elevado de transparência e é sujeito ao controle social. Todas as fases e detalhes da consulta nacional foram amplamente divulgados, como também os anais das conferências 
nacionais e os planos nacionais. A SPM vem publicando relatórios anuais a respeito de seu desempenho na implementação dos eixos de ação derivados do processo de consulta.

Um outro elemento que molda a relação entre a SPM e a sociedade civil organizada é a presença do CNDM (Conselho Nacional dos Direitos da Mulheres) em seu meio. O CNDM cria um importante canal de comunicação entre a APM e membros dos grupos de mulheres, concedendo à sociedade civil organizada acesso privilegiado aos mecanismos de monitoramento da execução dos planos de ação. Neste sentido, o CNDM desempenha um papel dual. Por um lado, age como uma espécie de advogado da SPM vis-à-vis o governo federal, constantemente lutando pelo aumento do poder da agência e do escopo desta no interior do aparelho de estado. Em maio de 2009, por exemplo, o Conselho publicou uma carta de protesto contra cortes no orçamento de 2009 da SPM e solicitou à equipe econômica do governo federal que liberasse a soma total dos recursos originalmente alocados à agência (CNDM, 2009). Ou seja, por ser composto por representantes da sociedade civil, o Conselho, em certas ocasiões, pode adotar uma postura crítica em relação ao governo federal - algo que a SPM, por ser parte da administração pública federal, não pode fazer. Por outro lado, o CNDM também exerce contínua pressão sobre a SPM para fazê-la implementar os planos nacionais da melhor maneira possível. A esse respeito, ativistas do movimento de mulheres mencionam que, a despeito de os grupos de mulheres terem um bom diálogo com a SPM, eles pressionam constantemente a agência para a implementação dos pontos concretos de ação?.

\section{Financiamento de projetos de gênero}

Uma terceira dimensão que dá evidência do padrão de relações entre SPM e sociedade civil organizada é o seu padrão de financiamento de projetos. Todos os anos desde que começou a funcionar em 2003, a

7 Entrevista com Santa Alves, da União Brasileira de Mulheres (em Brasília, 4 de junho de 2009) e com Isabel de Freitas, Marcha Mundial das Mulheres (em Brasília, 3 de junho de 2009). 
SPM concede financiamento através de competições nacionais para apoiar projetos que visem avançar o status das mulheres no Brasil.

De acordo com a literatura sobre feminismo estatal, em países com APMs eficazes como Austrália, Noruega e Dinamarca, as agências existentes oferecem linhas de financiamento para projetos com o objetivo último de empoderar as mulheres participantes desses projetos. Em outros casos menos exitosos, os programas de financiamento, quando existem, possuem diversos problemas, como viés de seleção (organizações aliadas ao governo federal recebem recursos) e problemas de administração dos recursos financeiros dos projetos (MCBRIDE STETSON e MAZUR, 1995). Estudos mostraram que, por exemplo, na Espanha, o Instituto de la Mujer (Instituto da Mulher) costumava utilizar $10-15 \%$ do seu orçamento anual ao programa de financiamento de projetos (VALIENTE, 1995) e que sua contraparte na Holanda também financiava um grande número de projetos (OUTSHOORN, 1995). No entanto, pouco é sabido a respeito dos detalhes desses financiamentos, tais como o montante total de recursos que as APMs alocam para esta atividade, quem recebe essas linhas de financiamento e quais projetos são financiados.

No caso da SPM, todas essas informações são de domínio público e todas as fases do programa de financiamento são transparentes. Cada competição nacional é amplamente divulgada e tanto instituições governamentais como não-governamentais podem participar (SPM, 2008a).

Os projetos vencedores dessas competições têm tido uma variedade grande de objetivos. Alguns envolvem organizações que prestam serviços diretamente às mulheres, como casas-abrigo que recebem mulheres em situação de violência. Outros projetos trabalham com o treinamento e capacitação de mulheres - como, por exemplo, projeto que ajudam a preparar mulheres interessadas em se tornar candidatas à vereança. Existem também projetos que preparam mulheres para a (re)-entrada no mercado de trabalho; que auxiliam mulheres a elaborar um plano de negócios para aumentar a lucratividade de suas atividades; e que as ensina a formar cooperativas 
para organizar a produção e comercialização de produtos e serviços. Além dos projetos que provêem serviços às mulheres, a SPM também apóia financeiramente a organização de eventos, encontros, workshops e conferências sobre temas relacionados aos direitos das mulheres, a criação de bancos de dados sobre a situação da mulher no Brasil e pesquisa científica sobre gênero.

Há três importantes aspectos do programa de financiamento de projetos da SPM que merecem ênfase: a porcentagem do orçamento da agência que é usado para esta atividade; o processo de concessão e gerenciamento do financiamento e o perfil dos recipientes do financiamento. Primeiro, no que se refere ao valor absoluto dos recursos destinados ao financiamento de projetos, a SPM gastou entre R\$ 3 milhões (2003) e $R \$ 34$ milhões (2007). O mais interessante, no entanto, é a porcentagem do orçamento da SPM dedicado a este programa. Desde a sua criação em 2003, a SPM tem devotado pelo menos 2/3 do seu orçamento ao financiamento de projetos (Figura 1). Estes números denotam um elevado grau de comprometimento da Secretaria com o objetivo de empoderar mulheres no Brasil.

Segundo, no que se refere ao processo de seleção dos projetos a serem financiados, é importante mencionar que a SPM convida ativistas dos movimentos de mulheres para participar dos comitês decisórios, que selecionam projetos e determinam o patamar de financiamento que eles receberão. A visão predominante entre os membros de organizações não-governamentais é a de que este processo de seleção se pauta pela imparcialidade ${ }^{8}$. No que tange à administração dos recursos obtidos, a SPM estabeleceu um sistema elaborado de prestação de contas, através do qual a Secretaria monitora como os recursos foram gastos e o grau de finalização de cada um dos objetivos propostos.

\footnotetext{
8 Entrevistas com Santa Alves, União Brasileira de Mulheres (em Brasília, 4 de junho de 2009) e com Natalia Mori, CFemêa (em Brasília, 5 de junho de 2009).
} 
Figura 1 - Orçamento da SPM (em R\$) e porcentagem alocada no financiamento de projetos

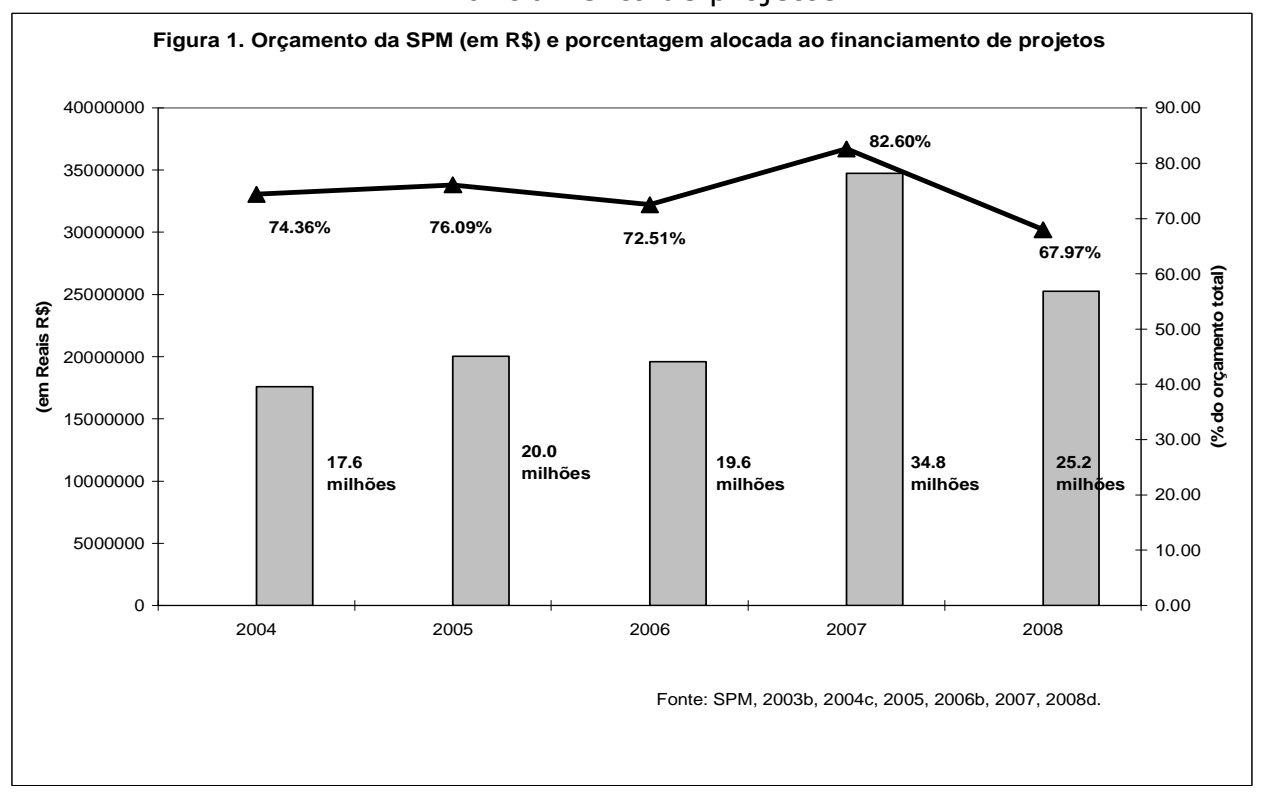

Fonte: SPM (2003, 2004b, 2005, 2006, 2007, 2008c).

Um terceiro aspecto peculiar do programa de financiamento de projetos da SPM refere-se ao perfil dos recipientes dos recursos (Figura 2). Tanto organizações de mulheres como instituições estatais (como prefeituras, secretarias estaduais etc.) podem concorrer no processo de seleção. Nos dois primeiros anos da competição, praticamente não houve diferença na quantidade de recursos alocados às entidades da sociedade civil organizada e aos atores estatais. Desde 2006, no entanto, os últimos têm recebido maior quantidade de recursos que seus contrapartes da sociedade civil. Em 2008, por exemplo, $81.3 \%$ dos recursos foram destinados a atores estatais. Os números de 2009 não foram divulgados ainda. 
Figura 2 - Alocação de recursos da linha de financiamento da SPM, por tipo de recipiente

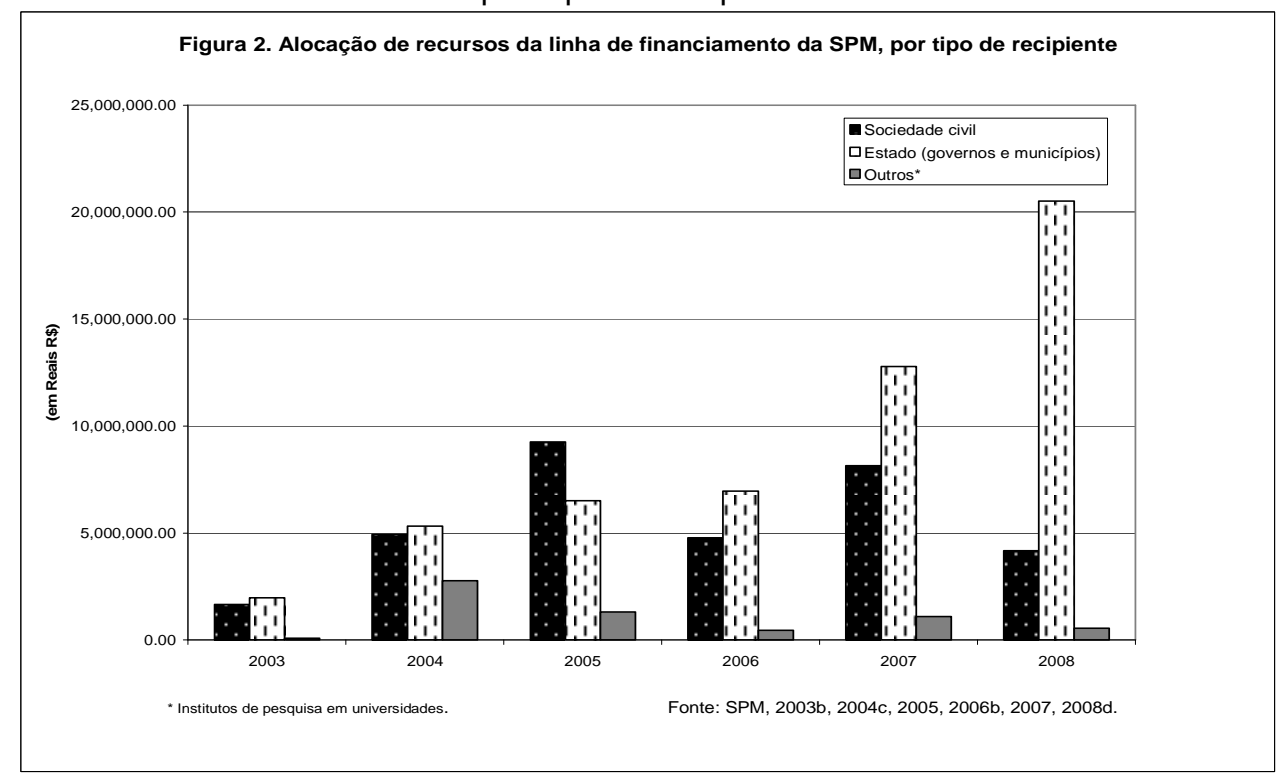

Fonte: SPM (2003, 2004b, 2005, 2006, 2007, 2008c).

É importante notar que, ao financiar atores estatais, a SPM está realizando demandas que organizações de mulheres apresentaram nas duas conferências nacionais e que foram incorporadas nos Planos Nacionais I e II. Uma dessas principais demandas foi o fortalecimento do aparato estatal no plano subnacional, de modo que cidades e estados possam estar adequadamente preparados para a total implementação de políticas públicas para mulheres.

Além disso, com esse objetivo de fortalecer a capacidade estatal de implementação de políticas públicas no plano subnacional, a SPM tem convidado estados e municípios a se comprometerem a adotar e pôr em prática os Planos Nacionais I e II. Em outubro de 2010, 20 estados (do total de 26 mais o Distrito Federal) tinham aderido ao plano. No que se refere aos municípios, ainda há muito trabalho a ser feito: apenas $18.7 \%$ deles possuem agências ou organismos de políticas públicas para mulheres (MUNIC, 2009).

\section{Considerações finais}

O objetivo deste artigo foi verificar o grau de sucesso do chamado feminismo estatal sob as duas administrações do Presidente 
Lula, do Partido dos Trabalhadores. De acordo com a literatura sobre o tema, as chamadas agências de políticas públicas para mulheres (APMs) têm maiores chances de êxito em duas situações. Primeiro, quando funcionam sob administrações que aumentem sua força institucional, o que usualmente ocorre sob governos de partidos progressistas e, segundo, quando a relação entre a APM e o movimento de mulheres se desenvolve sob uma dinâmica de cooperação. Esses dois elementos são essenciais à capacidade de a APM introduzir um olhar de gênero sobre as políticas públicas. Diante disso, este artigo buscou analisar a) o grau de comprometimento das administrações Lula com a SPM e b) o padrão de relação desta agência estatal com o movimento de mulheres.

Em relação ao primeiro tema, três pontos essenciais foram feitos. Em primeiro lugar, uma das principais fortalezas da SPM consiste na sua localização institucional no interior do Gabinete da Presidência. Como parte do Gabinete da Presidência, se torna menos difícil para a SPM tentar introduzir um componente de gênero às políticas públicas em um dos seus principais pontos de origem, quando ainda estão sendo formuladas nos ministérios e analisadas pela presidência.

Em segundo lugar, o status de ministério concedido à SPM pelo governo Lula também aumentou seu poder de ação no interior da administração federal. Isso porque garantiu à Secretaria sólido apoio administrativo e financeiro. Mais importante, a condição de ministro de estado dada à chefia da SPM provê essa agência com maior capacidade de se articular institucionalmente com ministérios e agências estatais, para convencê-los da importância da adoção de uma perspectiva de gênero no seu processo de tomada de decisões.

Em terceiro lugar, no que se refere ao suporte financeiro especificamente, o governo Lula tem dado mostras de substantivo e contínuo apoio à SPM. O orçamento anual da SPM cresceu significativamente no decorrer dos anos e sofreu cortes similares ou menores que os enfrentados por outras secretarias. Em resumo, as ações do governo Lula para com a SPM dão credibilidade à hipótese levantada pela literatura sobre feminismo estatal de que governos de 
partidos progressistas são mais propensos a criar as condições necessárias para a ação eficaz das APMs.

No que se refere à ação da SPM propriamente dita, sua relação com o movimento de mulheres, até o momento, valida a consideração feita pela literatura de que as agências estatais de políticas públicas para mulheres mais influentes são aquelas que cultivam laços estreitos com a sociedade civil organizada. Esse aspecto é extremamente importante, uma vez que APMs que carecem de pontos de contacto com o movimento de mulheres podem acabar implementando uma plataforma de ação que é totalmente divorciada das demandas e preocupações de grupos organizados, que possuem maior proximidade com os problemas concretos enfrentados pelas mulheres.

Nesse sentido, este artigo ressaltou que, desde sua criação, a SPM tem desenvolvido laços fortes com o movimento de mulheres no Brasil, gerando uma dinâmica de cooperação entre ambas as partes. Três são os elementos-chave dessa relação cooperativa. Primeiro, a presença do Conselho Nacional dos Direitos das Mulheres no interior da estrutura da SPM - o que fornece à sociedade civil um importante ponto de contacto com a agência estatal. Segundo, desde o início da chefia Freire, para elaborar sua plataforma de ação, a SPM tem posto em prática um processo elaborado de consulta nacional, altamente inclusivo, transparente e participativo, no qual as vozes de diferentes segmentos femininos foram incorporadas, formando um rico mosaico de demandas. Essa relação não pode ser caracterizada com um caso de cooptação, pelo estado, de grupos sociais organizados, nem como uma situação de captura de parte do aparelho de estado pela sociedade civil. A SPM não se apresenta como sendo uma porta-voz do movimento de mulheres. Pelo contrário, a SPM claramente se posiciona como sendo uma agência do governo federal e dados concretos dão credência a essa postura.

Como este artigo demonstrou, a SPM tem um programa de financiamento de projetos. O processo de seleção e de alocação de recursos conta com a participação da sociedade civil. No entanto, é feito de maneira considerada imparcial, sem privilegiar candidatos, como 


\section{DOSSIÊ OS ANOS LULA}

aconteceu no caso de APMs de outros países (MAZUR, 1995). O mais interessante é notar que um grande volume de recursos da SPM é destinado não às organizações de mulheres da sociedade civil - como um caso de captura do estado levaria a crer - mas às agências de políticas públicas estatais e municipais e a outros órgãos dos governos subnacionais.

Em suma, tanto as ações e o grau de comprometimento do governo Lula com a SPM quanto a relação desta com a sociedade civil organizada dão indicações firmes de que esta agência tem condições para transformar as femocratas em importantes atores na formulação, aprovação e efetiva implementação de políticas públicas para as mulheres brasileiras. Resta saber se a capacidade institucional atual da SPM será mantida com a mudança do chefe de governo e se seus mecanismos de consulta e sua dinâmica de cooperação com a sociedade civil sobreviverão a uma eventual mudança na chefia do órgão.

Simone R. Bohn é doutora em Ciência Política e Professora Assistente no Departamento de Ciência Política da York University, em Toronto no Canadá.

E-mail: sbohn@yorku.ca

\section{Referências:}

AGÊNCIA BRASIL. Luta pelos direitos das mulheres na Constituinte ficou conhecida como Lobby do Batom. Agência Brasil, 8 mar. 2008. Disponível em:

<http://http://www.agenciabrasil.gov.br/noticias/2008/03/05/materia.2 008-03-05.6242811352/view>. Acesso em: 24 ago. 2009.

ALVAREZ, Sonia. Engendering Democracy in Brazil: Women's Movements in Transition Politics. Princeton: Princeton University Press, 1990.

AMB. Políticas Públicas para Mulheres no Brasil: Balanço Nacional Cinco Anos Após Beijing. Brasília: Articulação de Mulheres Brasileiras, 2000.

ARTICULANDO. Entrevista - Solange Bentes Jurema. Articulando Eletronicamente, Recife, v. 1, n. 24, p. 1, dez. 2002a. 
- CNDM e SEDIM: Alguns consensus existentes na AMB. Articulando Eletronicamente, Recife, v. 1, n. 26, p. 1-2, dez. 2002b.

BRASIL. Presidência da República. Lei n. 7.353, de 29 de agosto de 1985. Cria o Conselho Nacional dos Direitos da Mulher - CNDM e dá outras providências. Brasília, 29 de agosto de 1985. Disponível em: <http://www.planalto.gov.br/ccivil_03/Leis/1980-1988/L7353.htm>. Acesso em: 24 ago. 2009.

BRASIL. Constituição (1988). A Constituição de 1988. Brasília: Senado Federal, 1999. a entrada estava como CONSTITUIÇÃO

- Medida Provisória n. 103, de 1 de janeiro de 2003. Dispõe sobre a organização da Presidência da República e dos Ministérios, e dá outras providências. Diário Oficial da União, Brasília, 1 jan. 2003a. Disponível em: <http://www.planalto.gov.br/ccivil_03/mpv/Antigas_2003/103.htm>. Acesso em: 24 ago. 2009.

Presidência da República. Lei n. 10.683, de 28 de maio de 2003. Dispõe sobre a organização da Presidência da República e dos Ministérios, e dá outras providências. Brasília, 28 de maio de 2003b. Disponível em: <http://www.planalto.gov.br/ccivil_03/Leis/2003/L10.683.htm>. Acesso em: 24 ago. 2009.

BYSTYDZIENSKI, Jill. Women's Equality Structures in Norway: Equal Status Council. In: McBRIDE STETSON, Dorothy; MAZUR, Amy G. (Eds.). Comparative State Feminism. Thousand Oaks: Sage. 1995. p. 186-202.

CNDM. Carta das Mulheres Brasileiras aos Constituintes. Brasília: Conselho Nacional dos Direitos da Mulher, 1986.

- Manifestação do CNDM pela Imediata Recomposição do Orçamento da Secretaria Especial de Políticas para Mulheres. Brasília: Plenário do Conselho Nacional dos Direitos das Mulheres, 2009.

CRENSHAW, Kimberle. Mapping the Margins: Intersectionality, Identity Politics and Violence against Women of Color. Stanford Law Review, Stanford, CA, v. 43, n. 6, p. 1241-99, jul. 1991.

JUREMA, Solange Bentes. Ações e estratégias do CNDM para o "empoderamento" das Mulheres. Revista Estudos Feministas, Florianópolis, v. 9, n. 1, p. 207-212, p. 2001.

LOVENDUSKI, Joni. State Feminism and Political Representation. Cambridge, UK: Cambridge University Press, 2005a. 
. Conclusions: state feminism and political representation. In: LOVENDUSKI, Joni (Ed.). State Feminism and Political Representation. Cambridge, UK: Cambridge University Press, 2005b. p. 260-293.

MAZUR, Amy. Strong State and Symbolic Reform: The Ministère des Droits de La Femme in France. In: McBRIDE STETSON, Dorothy; MAZUR, Amy (Eds.). Comparative State Feminism. Thousand Oaks: Sage, 1995. p. 76-94.

(Ed.). State Feminism, Women's Movement and Job Training: Making Democracies Work in a Global Economy. New York/London: Routledge, 2001.

MAZUR, Amy; McBRIDE STETSON, Dorothy. State Feminism since the 1980s: From Loose Notion to Operationalized Concept. Politics \& Gender, Washington D.C., v. 3, n. 4, p. 501-513, nov. 2007.

MCBRIDE STETSON, Dorothy (Ed.). Abortion Politics, Women's Movements and the Democratic State: a Comparative Study of State Feminism. Oxford: Oxford University Press, 2001.

McBRIDE STETSON, Dorothy; MAZUR, Amy. Introduction. In: McBRIDE STETSON, Dorothy; MAZUR, Amy (Eds.). Comparative State Feminism. Thousand Oaks: Sage, 1995. p. 1-21.

MUNIC. Perfil dos Municípios Brasileiros 2009. Rio de Janeiro: IBGE, 2009.

OUTSHOORN, Joyce. Administrative Accommodation in the Netherlands: The Department for the Coordination of Equality Policy. In: McBRIDE STETSON, Dorothy; MAZUR, Amy (Eds.). Comparative State Feminism. Thousand Oaks: Sage, 1995. p. 168-185.

(Ed.). The Politics of Prostitution: Women's Movements, Democratic States and the Globalization of Sex Commerce. Cambridge: Cambridge University Press, 2004.

SAWER, Marian. Sister in Suits: Women and Public Policy in Australia. Sydney: Allen \& Unwin, 1990.

. Femocrats in Glass Towers?: The Office of the Status of Women in Australia. In: McBRIDE STETSON, Dorothy; MAZUR, Amy (Eds.). Comparative State Feminism. Thousand Oaks: Sage, 1995. p. 22-39.

SEDH. Secretaria Especial de Direitos Humanos. 2009. Disponível em: <www.presidencia.gov.br/estrutura_presidencia/sedh>. Acesso em: 01 mar. 2009.

SPM. Convênios firmados por região. Brasília: Presidência da República, Secretaria Especial de Políticas Públicas para as Mulheres, 2003. 
SPM. Plano Nacional de Políticas Públicas para as Mulheres. Brasília: Presidência da República, Secretaria Especial de Políticas Públicas para as Mulheres, 2004a.

SPM. Convênios firmados por região/estado. Brasília: Presidência da República, Secretaria Especial de Políticas Públicas para as Mulheres, 2004b.

SPM. Convênios firmados por região/estado. Brasília: Presidência da República, Secretaria Especial de Políticas Públicas para as Mulheres, 2005.

SPM. Convênios firmados por região/estado. Brasília: Presidência da República, Secretaria Especial de Políticas Públicas para as Mulheres, 2006.

SPM. Convênios firmados por região/estado. Brasília: Presidência da República, Secretaria Especial de Políticas Públicas para as Mulheres, 2007.

SPM. Edital - Seleção de Projetos 2008. Brasília: Presidência da República, Secretaria Especial de Políticas Públicas para as Mulheres, 2008a.

SPM. II Plano Nacional de Políticas Públicas para as Mulheres. Brasília: Presidência da República, Secretaria Especial de Políticas Públicas para as Mulheres, 2008b.

SPM. Convênios firmados por região/estado. Brasília: Presidência da República, Secretaria Especial de Políticas Públicas para as Mulheres, 2008c.

SPM. Sobre a Secretaria. 2009. Disponível em: <www.presidencia.gov.br/estrutura_presidencia/sepm>. Acesso em: 28 fev. 2009.

TESOURO NACIONAL. Relatório Resumido da Execução Orçamentária do Governo Federal e Outros Demonstrativos. Brasília: Ministério da Fazenda, 2003.

Relatório Resumido da Execução Orçamentária do Governo

Federal e Outros Demonstrativos. Brasília: Ministério da Fazenda, 2004.

Relatório Resumido da Execução Orçamentária do Governo

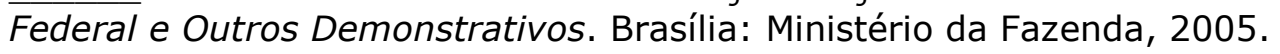

Relatório Resumido da Execução Orçamentária do Governo Federal e Outros Demonstrativos. Demonstrativo das Despesas da União por Poder e Órgão. Brasília: Ministério da Fazenda, 2006. 
Relatório Resumido da Execução Orçamentária do Governo

Federal e Outros Demonstrativos. Brasília: Ministério da Fazenda, 2007.

.Relatório Resumido da Execução Orçamentária do Governo

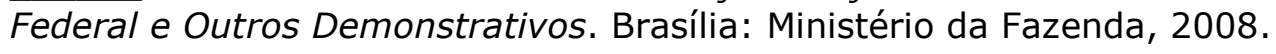

- Relatório Resumido da Execução Orçamentária do Governo Federal e Outros Demonstrativos. Brasília: Ministério da Fazenda, 2009.

VALIENTE, Celia. The Power of Persuasion: The Instituto de La Mujer in Spain. In: McBRIDE STETSON, Dorothy; MAZUR, Amy (Eds.). Comparative State Feminism. Thousand Oaks: Sage, 1995. p. 221-236.

WELDON, S. Laurel. The Structure of Intersectionality: A Comparative Politics of Gender. Politics and Gender, Washington D.C., v. 2, n. 2, p. 235-48, ago. 2006.

. Intersectionality. In: GOERTZ, Gary; MAZUR, Amy (Ed.). Politics, Gender and Concepts: Theory and Methodology. Cambridge, UK: Cambridge University Press, 2008. p. 121-144.

Texto recebido em 19/11/2010. Aprovado em 07/12/2010. 